\title{
Severe morbid obese patient undergoing laparoscopic sleeve gastrectomy and abdominoplasty
}

\begin{abstract}
Summary
Obesity is a chronic disease characterized by an increase of body fat with increased morbidity, disability and mortality and impairs quality of life Surgery is the most effective treatment for morbid obesity in terms of long-term weight loss that improves comorbidities and quality of life. A 50 year old woman weighing $250 \mathrm{~kg}$ with a height of $160 \mathrm{~cm}$ (BMI $97,66)$ was presented to the bariatric surgery department. The last two years she was unable to move because of her obesity and cruciate ligament rupture on the right knee and lipodystrophy of the abdominal wall. She was evaluated for laparoscopic sleeve gastrectomy and abdominoplasty. The patient underwent a successful sleeve gastrectomy and apronectomy. Three years after the operation the patient weight is $110 \mathrm{~kg}$ and is able to walk with orthopedic brace.
\end{abstract}

Volume 10 Issue 2 - 2018

\author{
Matsi J,' Nicolaou D, ${ }^{2}$ Ivanoviene $\mathrm{R}^{3}$ \\ 'Director of the Anesthesiology Department Limassol General \\ Hospital, Cyprus \\ ${ }_{2}$ MD MsC PhD General Surgeon Limassol General Hospital, \\ Cyprus \\ ${ }^{3}$ MD Anesthesiologist Limassol General Hospital, Cyprus
}

Correspondence: Despina Nicolaou MD, Director of the Anesthesiology Department Limassol General Hospital, Nikaias, Kato Polemidia, Limassol, Cyprus, Tel 0035725801100. Email denicola0@gmail.com

Received: April 02, 2018 | Published: April 17, 2018

\section{Introduction}

The WHO has already declared obesity a global epidemic that constitutes one of the biggest current health problems. ${ }^{1}$ In the European region, obesity also presents an unprecedented and underestimated public health challenge. ${ }^{2}$

Obesity is a chronic disease characterized by an increase of body fat. In clinical practice, the body fatness is assessed by the body mass index (BMI). BMI is calculated as measured body weight $(\mathrm{kg})$ divided by measured height squared $\left(\mathrm{m}^{2}\right)$. In adults obesity is defined by a BMI $\geq 30 \mathrm{~kg} / \mathrm{m}^{2}$ and overweight by a BMI between 25 and $29.9 \mathrm{~kg} / \mathrm{m}^{2}$

The cause of obesity is complex and multi-factorial., ${ }^{3,4}$ Obesity causes a significantly increased morbidity, disability and mortality and impairs quality of life. ${ }^{5-11}$ Surgery is the most effective treatment for morbid obesity in terms of long-term weight loss, ${ }^{12-14}$ improves comorbidities and quality of life, ${ }^{15}$ and in the long term decreases overall mortality. ${ }^{16,17}$ Surgery should be considered for patients in age groups from $18-60$ years with a BMI $\geq 40.0$ or with BMI between 35.0 and $39.9 \mathrm{~kg} / \mathrm{m}^{2}$ and co-morbidities in whom surgically induced weight loss is expected to improve the disorder (such as type 2 diabetes and other metabolic disorders, cardiorespiratory disease, severe joint disease and obesity-related severe psychological problems). ${ }^{18} \mathrm{~A}$ laparoscopic technique should be considered as the first treatment choice in bariatric surgery. ${ }^{19}$

\section{Case study and surgical procedure}

A 50 year old woman weighing $250 \mathrm{~kg}$ with a height of $160 \mathrm{~cm}$ (BMI 97,66). The last two years she was unable to move because of her obesity and cruciate ligament rupture on the right knee and lipodystrophy of the abdominal wall. She was evaluated for laparoscopic sleeve gastrectomy and abdominoplasty. Preoperative evaluation revealed that she was sleeping in a half-sitting position (she wasn't able to lie on her back), had limited effort capacity because of her generalized adiposity. She had a history of rheumatoid arthritis, arterial hypertension, asthma, iron deficiency, polyallergia (to Penicillin, Doxycycline, Septrin, Ampicillin, Aspirin, Librax) and depression. Her medication included Atrovent, Pulmicort, Xanax,
Losartan, Amlodipine, Hydrochlorothiazide, Vastarel, Alopurinol, Quinoric, and Cortisone. Laboratory tests recommended by the ABS, chest $\mathrm{x}$-Ray, ECG, Echocardiogram, arterial blood gas analysis were within normal range. Pulmonary function tests: FVC 48\%, FEV153\%, FEV1/FCV120\%, Conclusion - moderate to severe restriction. Her airway was graded as Mallampati class III, thyromental distance was $6 \mathrm{~cm}$ and sternomental distance was $9 \mathrm{~cm}$. She was accepted for anesthesia under ASA class 3.

Atrovent, Pulmicort nebulizers, Lorazepam, Omeprazole and Metoclopramide were given as premedication. After 3 min preoxygenation with $100 \%$ oxygen, anesthesia was induced with Midazolam, Fentanyl, Propofol, Rocuronium (titrating doses by LBW or TBW). Endotracheal intubation was performed using video laryngoscope (Cormack and Lehane Scale Grade III) with 8.5 cuffed endotracheal tube Anesthesia was maintained using infusions of Propofol Remifentanyl, Rocuronium and mixture of oxygen , air and Sevoflurane ( the doses varied at the different stages of surgery). The patient's lungs were ventilated with a 45/55 oxygen/air mixture using Pressure-controlled ventilation with a 1:1 inspiratory/expiratory ratio, Peak inspiratory pressure (Pinsp) adjusted to maintain the expiratory tidal volume at $10 \mathrm{ml} \mathrm{kg}$-1 IBW, and a respiratory rate adjusted to maintain the $\mathrm{PaCO}_{2}$ at $5 \mathrm{kPa}$, using Positive End Expiratory Pressure (PEEP) 6-8 $\mathrm{cm} \mathrm{H}_{2} \mathrm{O}$.

The effects of intraoperative intermittent positive pressure ventilation (IPPV) regimens on physiological variables are reported in bariatric patients. ${ }^{24-28}$ Currently, the translation of these data into effects on postoperative pulmonary complications and outcomes is lacking for the bariatric population. A using of positive end expiratory pressure (PEEP) and recruitment improved intraoperative oxygenation and pulmonary mechanics. In a wider surgical population, adoption of the other elements of lung protective ventilation (LPV) was associated with significant reduction in postoperative complications. ${ }^{29}$

Patient positioning affects pulmonary function perioperative. ${ }^{30}$ The "beach chair" and "leg flexion position" have been demonstrated to be superior to straight, supine position regardless of Trendelenburg angle. These pulmonary effects are most marked in the absence of 
the intraoperative pneumoperitoneum. ${ }^{31}$ However, they may have negative influence on surgical access with consequent need of increased insufflation pressures. ${ }^{32}$

ECG, Blood Pressure $\mathrm{SpO}_{2} \mathrm{ETCO}_{2}$, PAP (Peak Airway Pressure) arterial blood gas, CVP, and Urine output were continuously monitored during the surgery. Abdominoplasty was performed and then pneumoperitoneum was created, the intraabdominal pressure was about $14 \mathrm{mmHg}$ for $2 \frac{1}{2}$ hours without having any extreme hemodynamic alteration. Low-pressure carboperitoneum minimizes adverse haemodynamic effects ${ }^{21}$ but may not ensure optimal surgical conditions, especially in the presence of inadequate NMB. ${ }^{22,23}$ Deep NMB promotes a low-pressure $(<1.6 \mathrm{kPa})$ peritoneum while providing adequate surgical access and visualization[22,23].It minimizes cardiac dysfunction associated with high IAP and reduces postoperative pain intensity, incidence of shoulder pain, and analgesic consumption, compared with moderate NMB..$^{20,22,23}$

The surgery was uneventful and it lasted about $5 \frac{1}{2}$ hours. At the end of the operation Morfine and Paracetamol was given for analgesia. The patient was transferred intubated to the ICU for further observation At the ICU $10 \mathrm{cmH} 2 \mathrm{O}$ PEEP in ASV (Adopted Supportive Ventilation) was applied and Fentanyl infusion for analgesia was started. The patient was extubated at the 6 postoperative hour. After extubation a respiratory physiotherapy with a hand respirometer was applied. The postoperative period was uneventful and the patient left the hospital at the 5 postoperative day. Three years after the operation the patient weight is $110 \mathrm{~kg}$ and is able to walk with orthopedic brace (Figure 1) (Figure 2).
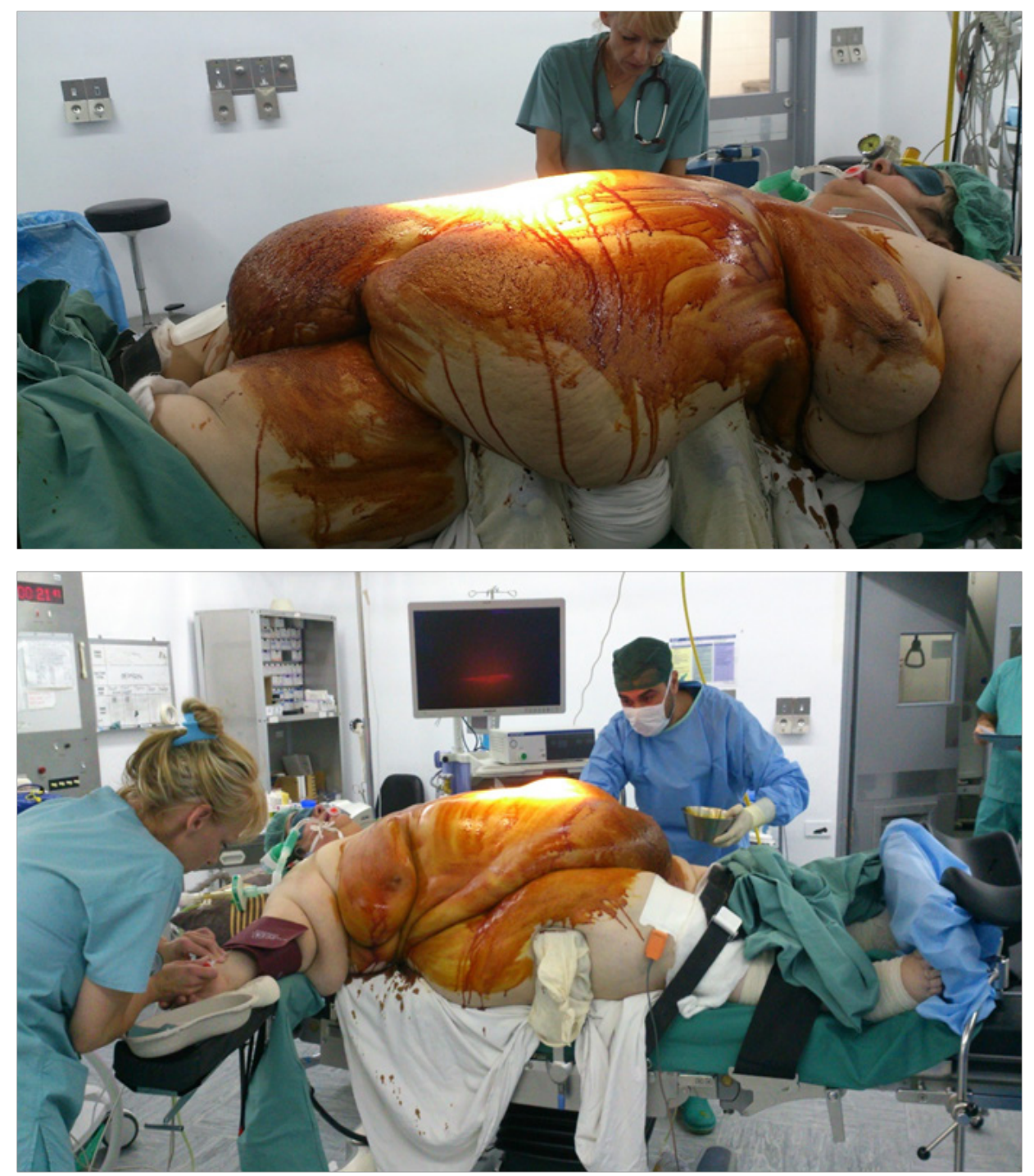

Figure I Before Apronectomy and Sleevegastrectomy. 

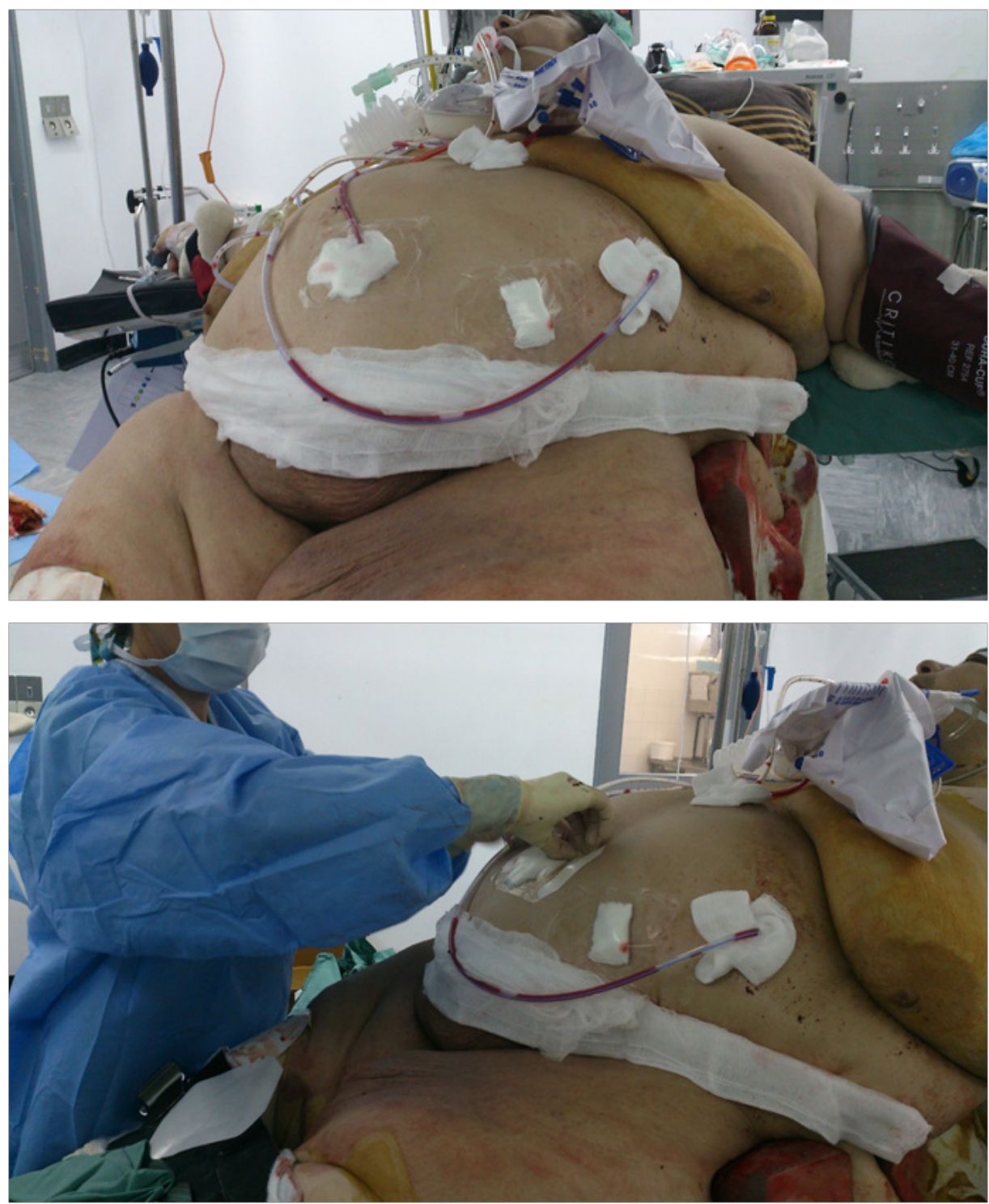

Figure 2 After Apronectomy and Sleevegastrectomy.

\section{Conclusion}

The number of obese patients has more than doubled in the last 10 years unfortunately. Obesity has been identified as a significant risk factor for respiratory and infectious complications in general surgery and for anesthesia related mortality. Furthermore the Anesthetists and the Surgeons frequently have to deal with the technical difficulties regarding morbid obese patients. Preoperative and a multidisciplinary team approach is very important for the success of the intervention and the safety of the severe morbid obese patient during laparoscopic surgery.

\section{References}

1. WHO. Obesity: Preventing and managing the global epidemic. Report of a WHO consultation. Geneva, WHO Technical Report Series 894, 2000
2. James WP. The epidemiology of obesity: the size of the problem. J Intern Med. 2008;263(4):336-52.

3. Yanovski SZ, Yanovski JA. Obesity. N Engl J Med. 2002;346(8):591602 .

4. Haslam DW, James WP. Obesity. Lancet. 2005;366(9492):1197-209.

5. Banegas JR, López-García E, Gutiérrez-Fisac JL, et al. A simple estimate of mortality attributable to excess weight in the European Union. Eur $J$ Clin Nutr. 2003;57(2):201-8.

6. Adams KF, Schatzkin A, Harris TB, et al. Overweight, obesity and mortality in a large prospective cohort of persons 50 to 71 years old. $N$ Engl J Med. 2006;355(8):763-78.

7. Flegal KM, Graubard BI, Williamson DF, et al. Cause-specific excess death associated with underweight, overweight and obesity. JAMA. 2007;298(17):2028-37. 
8. Renehan AG, Tyson M, Egger M, et al. Body-mass index and incidence of cancer: a systematic review and meta-analysis of prospective observational studies. Lancet. 2008;371(9612):569-78.

9. Stevens J, Cai J, Evenson KR, et al. Fitness and fatness as predictors of mortality from all causes and from cardiovascular disease in men and women in the Lipid Research Clinics Study. Am J Epidemiol. 2002;156(9):832-841.

10. Roberts RE, Deleger S, Strawbridge WJ, et al. Prospective association between obesity and depression: evidence from the Alameda County Study. Int J Obes Relat Metab Disord. 2003;27(4):514-21.

11. Linde JA, Jeffery RW, Levy RL, et al. Binge eating disorder, weight control self-efficacy, and depression in overweight men and women. Int J Obes Relat Metab Disord. 2004;289(3):418-25.

12. Ridley N. Expert panel on weight loss surgery-executive report. Obes Surg. 2005;13:206-26

13. Levy P, Fried M, Santini F, et al. The comparative effects of bariatric surgery on weight and type 2 diabetes. Obes Surg. 2007;17(9):1248-56.

14. Maggard MA, Shugarman LR, Suttorp M, et al. Meta-analysis: surgical treatment of obesity. Ann Intern Med. 2005;142(7):547-59.

15. Sjöström L, Narbro K, Sjöström CD, et al. Effects of bariatric surgery on mortality in Swedish obese subjects. NEngl J Med. 2007;357(8):741-52.

16. Sjöström L, Lindroos AK, Peltonen M, et al. Swedish Obese Subjects Study Scientific Group: Lifestyle, diabetes, and cardiovascular risk factors 10 years after bariatric surgery. $N$ Engl J Med. 2004;351(26):2683-93.

17. Adams TD, Gress RE, Smith SC, et al. Long-term mortality after gastric bypass surgery. N Engl J Med. 2007;357(8):753-61.

18. Fried M, Hainer V, Basdevant A, et al. Interdisciplinary European guidelines on surgery of severe obesity. Obesity Facts. 2008;1(1):52-58.

19. van Dielen FM, Soeters PB, de Brauw LM, et al. Laparoscopic adjustable gastric banding versus open vertical banded gastroplasty: a prospective randomized trial. Obes Surg. 2005;15(9):1292-8.

20. Gurusamy KS, Samraj K, Davidson BR. Low pressure versus standard pressure pneumoperitoneum in laparoscopic cholecystectomy. Cochrane Database Syst Rev. 2009;2:CD006930

21. Dexter SP, Vucevic M, Gibson J, et al. Hemodynamic consequences of high- and low-pressure capnoperitoneum during laparoscopic cholecystectomy. Surg Endosc. 1999;13(4):376-81.
22. Geldner G, Niskanen M, Laurila P, et al. A randomised controlled trial comparing sugammadex and neostigmine at different depths of neuromuscular blockade in patients undergoing laparoscopic surgery. Anaesthesia. 2012;67(9):991-8.

23. Martini CH, Boon M, Bevers RF, et al. Evaluation of surgical conditions during laparoscopic surgery in patients with moderate vs deep neuromuscular block. Br J Anaesth. 2014;112(3):498-505.

24. Erlandsson K, Odenstedt H, Lundin S, et al. Positive endexpiratory pressure optimization using electric impedance tomography in morbidly obese patients during laparoscopic gastric bypass surgery. Acta Anaesthesiol Scand. 2006;50(7):833-839.

25. Reinius H, Jonsson L, Gustafsson S, et al. Prevention of atelectasis in morbidly obese patients during general anesthesia and paralysis: a computerized tomography study. Anesthesiology. 2009;111(5):979-987.

26. Talab HF, Zabani IA, Abdelrahman HS, et al. Intraoperative ventilatory strategies for prevention of pulmonary atelectasis in obese patients undergoing laparoscopic bariatric surgery. Anesth Analg. 2009;109(5):1511-1516

27. Whalen FX, Gajic O, Thompson GB, et al. The effects of the alveolar recruitment maneuver and positive end-expiratory pressure on arterial oxygenation during laparoscopic bariatric surgery. Anesth Analg. 2006;102(1):298-305

28. Bohm SH, Thamm OC, von Sandersleben A, et al. Alveolar recruitment strategy and high positive end-expiratory pressure levels do not affect hemodynamics in morbidly obese intravascular volume-loaded patients. Anesth Analg. 2009;109(1):160-163.

29. Futier E, Constantin JM, Paugam-Burtz C, et al. A trial of intraoperative low-tidal-volume ventilation in abdominal surgery. $N$ Engl $\mathrm{J}$ Med. 2013;369(5):428-437

30. Dixon BJ, Dixon JB, Carden JR, et al. Preoxygenation is more effective in the 25 degrees head-up position than in the supine position in severely obese patients: a randomized controlled study. Anesthesiology. 2005;102(6):1110-1115.

31. Valenza F, Vagginelli F, Tiby A, et al. Effects of the beach chair position, positive end-expiratory pressure, and pneumoperitoneum on respiratory function in morbidly obese patients during anesthesia and paralysis. Anesthesiology. 2007;107(5):725-732.

32. Mulier JP, Dillemans B, Van Cauwenberge S. Impact of the patient's body position on the intraabdominal workspace during laparoscopic surgery. Surg Endosc. 2010;24(6):1398-1402. 